\title{
NOTE
}

\section{Influence of Dexamethasone on TRF Induced TSH Release in Rats}

\author{
Hiroyoshi FUKATSU, Masahiro SAKODA and Sigeaki BABA \\ 2nd Department of Internal Medicine, Kobe University School \\ of Medicine, Kobe
}

\section{Synopsis}

\begin{abstract}
The effect of dexamethasone pretreatment on $\mathrm{TSH}$ release induced by synthetic TRF was investigated in rats.

Plasma TSH levels were measured by means of McKenzie's method with a slight modification.

Dexamethasone was injected 4 hours before TRF administration. Blood samples were withdrawn from the jugular vein $10 \mathrm{~min}$ after TRF injection.

In a group received single dexamethasone pretreatment, TSH release following the TRF administration was significantly enhanced when compared with those observed in the saline pretreated group.

However, the increase in TSH release was not observed in the rats treated chronically by dexamethasone for 15 days.

The mechanism responsible for this dexamethasone effect on $\mathrm{TSH}$ secretion induced by TRF exists at hypothalamic level.
\end{abstract}

Although many factors are thought to be correlated to the mechanism of pituitary TSH secretion, the regulation of TSH release is closely related to TRF and serum thyroxine concentration (Shinha et al., 1965; Vale et al., 1967; Tsuji et al., 1969).

However, TSH release is also influenced by other hormone concentrations in the serum, for example estradiol (Fisher et al., 1971; D’Angelo et al., 1969) and especially dexamethasone.

Sakiz and Guillemin (1965) showd that inhibition of adrenocorticotropic function by dexamethasone treatment gave rise to stimulation of thyrotropic function and vice versa. This inverse relationship between ACTH and TSH is designated as "shift change" in the thyroid-adrenal relation.

It is generally felt that the increased TSH

Received for publication January 11, 1973. secretion leads to decreased ACTH secretion with some exceptions.

The purpose of this report was to investigate the influence of dexamethasone pretreatment on TRF induced TSH release in rats.

\section{Materials and Methods}

Adult male rats (Swiss-Webster strain) weighing $150 \mathrm{~g}$ were used for the experiment. They were fed Oriental M-F diet. Water was given ad libitum.

Dexamethasone was injected i.p. at 9:00 a.m.

Synthetic TRF was injected into a jugular vein under pentobarbital anesthesia $(4.5 \mathrm{mg} / 100 \mathrm{~g} \mathrm{B.W}$., i.p.) $4 \mathrm{hr}$ after dexamethasone treatment. $10 \mathrm{~min}$ after TRF injection blood was withdrawn from a jugular vein in a heparinized syringe and centrifuged.

The serum was stored at $-20^{\circ} \mathrm{C}$ until use. As a control, saline was injected i.p. instead of dexamethasone.

In the case of daily administration (chronic treatment), dexamethasone was given i.p. at 9:00 a.m. once a day for 15 days. 
experimental design

acute treatment

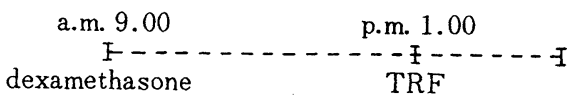

chronic treatment

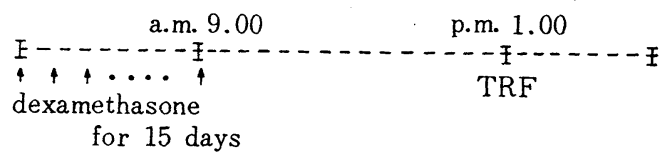

Fig. 1

TRF was given $4 \mathrm{hr}$ after the last dexamethasone treatment (Fig. 1). Each group was composed of 5 rats. McKenzie's method with a slight modification was employed for TSH assay and $0.1 \mathrm{mU}$ of TSH could be detectable. $0.4 \mathrm{ml}$ of rat serum was injected into a tail vein of a mouse. Eight mice were used for single TSH determination. Synthetic TRF (pyro-glutamylhistidyl-proline-amide) was supplied by the Daigo Nutritive Chemicals Co. Ltd., Tokyo, Japan.

Student's " $t$ " test was employed for statistical analysis.

\section{Result}

1. Effect of TRF on plasma TSH levels in the rets received a single pretreatment of dexamethasone. As shown in Table 1, the basal levels of plasma TSH were not detectable with the method employed. $10 \mu \mathrm{g}$ or $500 \mu \mathrm{g}$ of dexamethasone caused a marked elevation of plasma TSH level after TRF ( $2.5 \mathrm{ng})$ injection when compared to those of saline pretreated rats. When $10 \mathrm{ng}$ of TRF was administered, the increase of plasma TSH
Table 1. Effect of dexamethasone on TSH secretion in rats

\begin{tabular}{|c|c|c|c|}
\hline Treatment & $\begin{array}{l}\text { Blood ratio- } \\
\text { activity } \% \text { of } \\
\text { initial } \\
\text { mean } \pm \text { S.E. }\end{array}$ & $\underset{\mathrm{mU} / \mathrm{m} l}{\mathrm{TSH}}$ & $\mathbf{P}$ \\
\hline $\begin{array}{l}\text { Before dex. } \\
\text { injection }\end{array}$ & $108 \pm 23.0$ & $0.12 \pm 0.74$ & - \\
\hline $\begin{array}{l}2 \mathrm{hr} \text { after dex. } \\
\text { injection }\end{array}$ & $95.2 \pm 7.34$ & $<0.1$ & n.s. \\
\hline $\begin{array}{c}4 \mathrm{hr} \text { after dex. } \\
\text { injection }\end{array}$ & $95.4 \pm 10.9$ & $<0.1$ & n.s. \\
\hline $\begin{array}{l}6 \mathrm{hr} \text { after dex. } \\
\text { injection }\end{array}$ & $100 \pm 5.50$ & $<0.1$ & n.s. \\
\hline
\end{tabular}

dexamethasone phosphate; $100 \mu \mathrm{g} / 100 \mathrm{~g}$ b.w. i.p. $4 \mathrm{hr}$ before TRF administration. $n=8$.

level comparing with the control (TRF $10 \mathrm{ng}$, saline pretreated rats) was also observed.

2. Effect of TRF on plasma TSH levels in the rats received chronic pretreatment of dexamethasone. The result in the table 3 indicates that the rise of resting level of plasma TSH by dexamethasone pretreatment was not observed in rats received daily dexamethasone injection. Chronic dexamethasone pretreatment had no influence on TRF induced TSH release in these doses of TRF and dexamethasone.

\section{Discussion}

It has been well recognized that TSH secretion is regulated primarily by TRF and serum thyroxine concentration as described

Table 2. Effect of dexamethasone on TSH secretion by synthetic TRF in acute treatment

\begin{tabular}{lllll}
\hline & Dex. & \multicolumn{4}{c}{ Plasma TSH mU/ml } \\
\cline { 2 - 5 } TRF & Saline & Dex. 10 $\mu \mathrm{g}$ & Dex. 100 $\mu \mathrm{g}$ & Dex. 500 $\mu \mathrm{g}$ \\
\hline Before TRF inj. & $0.156 \pm 0.026$ & $0.16 \pm 0.060$ & $0.21 \pm 0.057$ & $0.19 \pm 0.043$ \\
TRF 2.5 ng & $0.28 \pm 0.083$ & $0.93 \pm 0.15^{*}$ & $0.44 \pm 0.029$ & $0.81 \pm 0.15^{*}$ \\
TRF 10 ng & $0.92 \pm 0.093$ & $1.2 \pm 0.31$ & $1.3 \pm 0.18$ & $1.2 \pm 0.30$ \\
\hline
\end{tabular}

Dexamethasone or saline was administered i.p. $4 \mathrm{hr}$ before TRF injection.

Blood was collected 10 min after TRF injection. $n=7$.

$* \mathrm{p}<0.05$ 
Table 3. Effect of dexamethasone on TSH secretion induced by TRF in chronic treatment

\begin{tabular}{cccc} 
Dex. & \multicolumn{3}{c}{ plasma TSH mU/m $l$} \\
\cline { 2 - 4 } TRF & saline & dex. $2 \mu \mathrm{g}$ & dex. $10 \mu \mathrm{g}$ \\
\hline $\begin{array}{c}\text { Before TRF } \\
\text { injection }\end{array}$ & $<0.1$ & $<0.1$ & $<0.1$ \\
TRF 2.5 ng & $0.24 \pm 0.065$ & $0.15 \pm 0.034$ & $0.36 \pm 0.10$ \\
TRF 10 ng & $0.35 \pm 0.12$ & $0.58 \pm 0.11$ & $0.34 \pm 0.12$ \\
\hline
\end{tabular}

Dexamethasone was administered i.p. $4 \mathrm{hr}$ before TRF injection. $n=7$.

before (Sinha and Meites, 1965). However, the secretion of a pituitary hormone affects the secretion rate of other pituitary hormones.

For example, an inverse relationship between ACTH and TSH secretion has been called "shift change" with some exceptions as seen in cold stress (Brown-Grant, 1960) and exogenous administration of TRF during stress (Sakiz and Guillemin, 1965).

The present experiment dealt with dexamethasone effect on TSH secretion following synthetic TRF injection.

As seen in Table 2, the increase of plasma TSH level in the TRF induced TSH release was higher in the rats received the single dexamethasone pretreatment than the control (saline pretreated rats). Especially significant increase of plasma TSH level was observed in the rats received TRF ( $2.5 \mathrm{ng})$ and dexamethasone $(10 \mu \mathrm{g}$ or $500 \mu \mathrm{g})$.

When dexamethasone was administered for 15 days, a significant increase in TSH release was not observed as seen in Table 3 .

Ducomman et al. (1966) showed that TSH concentration in the serum was within a range, of normal limit 5 hours after dexamethasone injection in rats.

So far in the most cases, the effect of dexamethasone on TSH release was investigated employing PBI or ${ }^{131}$ I-uptake measurement instead of direct assay of TSH (Langer and Lichardus, Albert, 1952; Ingbar and Frenkel, 1956). Wilber and Utiger (1969) reported that the administration of dexamethasone intravenousely to anesthetized normal rats was followed by a significant fall in plasma TSH and incubation of pituitaries with either dexamethasone or corticosterone did not result in inhibition of TRF stimulation. As a result, they concluded that glucocorticoid action was exerted at a suprahypophyseal level and led to inhibition of the TRF secretion.

In our experiment, the augmented TSH secretion by TRF in a single dexamethasone pretreatment is thought to be the result of good response to extrinsic TRF due to decreased hypothalamic (intrinsic) TRF.

What is the difference between acute and chronic dexamethasone treatment? Sakoda et al. described that decreased TSH response to TRF was observed in patients of Cushing's syndrome and chronically dexamethasone treated patients. In these patients, glucocorticoid was given in a large dose and for long duration.

In a case of short-term or intermitten glucocorticoid treatment, TSH response to synthetic TRF was remained to be normal or even elevated. (Sakoda et al., 1972)

In our study, 15 days pretreatment was considered to be intermediate between acute and chronic treatment.

$\mathrm{TSH}$ secretion from the anterior pituitary is not only regulated by TRF and serum thyroxine concentration, but also modified by other hormone secretions especially

glucocorticoid. Acceleration or inhibition of TSH release by dexamethasone treatment depends on dose and duration of dexamethasone treatment.

\section{References}

Albert, A. (1952). Ann. Rev. Physiol. 14, 418. Brown-Grant, K. (1960). J. Physiol. 151, 40.

D'Angelo, S. A., and J. S. Fisher (1969). Endocrinology 84, 117.

Ducomman, R. (1966). Am. J. Physiol. 210, 1257.

Fisher, J. S., and S. A. D'Angelo (1971). 
Endocrinology 88, 687.

Ingbar, S. H., and W. Frenkel (1956). Metabolism 5, 653 .

Langer, P., and B. Lichardus (1969). Neuroendocrinol. 4, 112.

Sakoda, M., M. Ohtsuki, M. Ohkubo and S. Baba (1972). Folia Endocrinol. Japon. 20, 206. (In Japanese).

Sakiz, E., and R. Guillemin (1956). Endocri- nology 77, 797.

Sinha, D., and J. Meites (1965). Neuroendocri. nology $\mathbf{1}, 4$.

Tsuji, S., M. Sakoda, and H. Fukatsu (1969). Endocrinol. Japon. Suppl. 1, 35.

Vale, W., and R. Guillemin (1967). Proc. Soc. Exp. Biol. Med. 125, 210.

Wilber, J. F. and R. D. Utiger (1969). J. Clin. Inv. 48, 2096. 